\title{
Preventive Effect of Liupao Tea Polyphenols on HCl/ Ethanol-Induced Gastric Injury in Mice
}

\author{
Kai Zhu, ${ }^{1,2,3}$ Peng Peng, ${ }^{4}$ Ning Wu, ${ }^{1}$ Xianrong Zhou, ${ }^{1,2,3}$ Jianfei Mu, ${ }^{1,2,3}$ and Xin Zhao $\mathbb{D}^{1,2,3}$ \\ ${ }^{1}$ Chongqing Collaborative Innovation Center for Functional Food, Chongqing University of Education, Chongqing 400067, China \\ ${ }^{2}$ Chongqing Engineering Research Center of Functional Food, Chongqing University of Education, Chongqing 400067, China \\ ${ }^{3}$ Chongqing Engineering Laboratory for Research and Development of Functional Food, Chongqing University of Education, \\ Chongqing 400067, China \\ ${ }^{4}$ Department of Gastroenterology, Emergency Medical Center of Chongqing, \\ The Affiliated Central Hospital of Chongqing University, Chongqing 400014, China
}

Correspondence should be addressed to Xin Zhao; zhaoxin@cque.edu.cn

Received 14 June 2019; Revised 16 November 2019; Accepted 16 January 2020; Published 11 February 2020

Academic Editor: Teresa Zotta

Copyright ( 2020 Kai Zhu et al. This is an open access article distributed under the Creative Commons Attribution License, which permits unrestricted use, distribution, and reproduction in any medium, provided the original work is properly cited.

\begin{abstract}
Liupao tea is a traditional Chinese tea drink. The preventive effect of crude polyphenols in Liupao tea on $\mathrm{HCl} /$ ethanol-induced gastric injury was investigated in this study. After a model of gastric injury in mice was established, mouse serum and tissues were analyzed by biochemical and molecular biological methods. The results showed that Liupao tea polyphenols (LTPs) could effectively reduce the area of gastric mucosal lesions, decrease the volume of gastric juice, and increase the $\mathrm{pH}$ of gastric juice in mice with gastric injury. Observations of the pathology revealed that LTPs could alleviate cell necrosis and gastric mucosal injury in mice with gastric injury. The SOD activity and GSH level were decreased in mice after gastric injury, while the level of MDA was increased. LTPs could inhibit the changes caused by gastric injury and make the SOD activity, GSH, and MDA levels close to the normal levels. In addition, LTPs could upregulate the mRNA expression of $\mathrm{Cu} / \mathrm{Zn}$-SOD, Mn-SOD, CAT, nNOS, and eNOS and downregulate the expression of iNOS in the gastric tissue of mice with gastric injury. Therefore, LTPs can effectively prevent $\mathrm{HCl} /$ ethanol-induced gastric injury. HPLC analysis showed that LTP contains six bioactive substances of gallic acid, catechin, caffeine, epicatechin, epigallocatechin gallate, and epicatechin gallate, so the effect of LTP might mainly come from these six components. The effect of a high concentration of LTP is similar to that of ranitidine. LTPs represent a kind of active substance with a protective effect on gastric tissue.
\end{abstract}

\section{Introduction}

Liupao tea is black tea named after the town where it was discovered: Liubao Township, Cangwu County, Wuzhou City, Guangxi Province. Because of its unique areca aroma, this tea has been listed as 1 of 24 varieties of Chinese tea [1]. The mice research shows that Liupao tea contains not only various essential amino acids, vitamins, and trace elements but also more lipid-decomposing enzymes than other types of tea. Therefore, long-term drinking of Liupao tea has a strong effect on lipid metabolism in processes such as decomposing fat and reducing fat compounds, cholesterol, and triglycerides, and it also helps with weight loss and contributes to fitness [2]. Modern scientific animal experiment research has found that tea is helpful as an antioxidant, antitumor, antibacterial, and antivirus agent; as an ameliorating compound in hypoglycemia and hypotension; and as contributor to fat reduction, weight reduction, cancer prevention, and radiation protection, and the polyphenols contained in tea play a main role in these functions [3-5]. Furthermore, some studies have shown that the polyphenol content in Liupao tea is lower than that in green tea, but the epigallocatechin gallate and epicatechin gallate content in Liupao tea is higher. There are abundant polyphenols and theanine in Liupao tea, which have strong antioxidant capacity [6]. 
Alcohol-induced gastric injury is a mucosal injury caused by excessive drinking that is often manifested as gastritis in the clinic [7]. Ethanol can directly damage gastric epithelial cells and submucosal vessels. Ethanol directly damages gastric mucosal epithelial cells, thus destroying the gastric mucosal barrier. Hydrophobic alkyl groups and hydrophilic hydroxyl groups of the ethanol molecules can directly destroy the defense system of the gastric mucosa, which in turn makes the gastric mucosa vulnerable to various digestive enzymes, bile, and gastric acid, causing further $\mathrm{H}^{+}$antidiffusion, thereby aggravating the damage to the gastric mucosa. Ethanol can cause injury to the submucosal vascular endothelium and can cause dilatation of blood vessels, rupture of small blood vessels, submucosal hemorrhage, and other changes that further destroy the mucosal barrier. As damage to the mucosal epithelium and vascular endothelium activates many inflammatory mediators, alcohol consumption can also cause neutrophil infiltration and further aggravate mucosal damage [8]. In addition, a high concentration of ethanol has a strong stimulating effect on the gastric mucosa, which can lead to the necrosis of mucosal epithelial cells [9]. Currently, the frequent occurrence of gastritis, gastric ulcers, gastric perforation, gastric bleeding, and other gastric diseases is drawing attention to alcohol-induced gastric injury. The preventive effect and application of bioactive substances on alcohol-induced gastric injury have also become hot topics in research and in drug treatment. In this study, hydrochloric acid was added as inducer to increase the effect of alcohol to induce gastric injury. Cu/Zn-SOD, Mn-SOD, and CAT are all sensitive indexes of oxidative damage. Ethanol/ $\mathrm{HCl}$ can cause severe oxidative stress in gastric tissue, which makes $\mathrm{Cu} / \mathrm{Zn}-\mathrm{SOD}, \mathrm{Mn}-\mathrm{SOD}$, and CAT change greatly [7]. NOS exists in normal gastric tissue, and NOS will change significantly after gastric tissue injury. eNOS, nNOS, and iNOS will change accordingly [9]. Therefore, this study also chose these sensitive indicators for research.

At present, there are few studies on Liupao tea polyphenols (LTPs), and there is insufficient understanding of the potential application of the active substances in this natural beverage. In this study, the polyphenols of Liupao tea were extracted by ion precipitation method. The polyphenols of Liupao tea with high purity were studied to verify the effect of the most important active substances in conventional tea water. A mouse model of alcoholic gastric injury was established to observe the preventive effect of LTPs on alcohol-induced gastric injury; furthermore, the mechanism of LTPs on oxidative stress induced by gastric injury in mice was specifically observed. Liupao tea is only used as a nonmedicinal drink at present. The serum and tissue of mice were analyzed by biochemical detection techniques and molecular biology experiments. With the results of this study, new ideas for the further application of Liupao tea are advanced, and in particular, the mechanism of the Liupao tea extracts is explained in detail to add to an accumulating theoretical basis for better application of functional consumables with biological activity. Although only focused on experimental animals, this study also laid the foundation for further clinical research on LTPs.

\section{Materials and Methods}

2.1. Extraction of Tea Polyphenols. First, Liupao tea was crushed into powder by instant grinding method to form tea powder of more than 600 mesh. Liupao tea $(100 \mathrm{~g})$ was added to $45 \%$ (volume ratio) of $150 \mathrm{~mL}$ of ethanol solution. The extract was heated in a constant temperature water bath (90 C) for $30 \mathrm{~min}$. After the extraction was repeated, two extracts were combined. The $\mathrm{pH}$ of the combined extract was adjusted to 6.1 (15\% hydrochloric acid solution was used). A mixed precipitator consisting of $160 \mathrm{~mL}$ of $\mathrm{AlCl}_{3}(6 \mathrm{~g})$ and $\mathrm{ZnCl}_{2}$ (12 g) was added to the precipitate. The mixture was centrifuged $(3000 \mathrm{r} / \mathrm{min})$ for $10 \mathrm{~min}$ and retained for precipitation. Then, $200 \mathrm{~mL}$ of hydrochloric acid (12\% volume ratio) was added to the precipitate collected after the centrifugation for transdissolution. The supernatant was separated by centrifugation and then extracted by adding $450 \mathrm{~mL}$ of ethyl acetate in aliquot fractions [10]. The polyphenol extract was obtained by combining the extracts and subjecting them to rotating evaporation.

2.2. Determination of Polyphenols by HPLC. The $10 \mathrm{mg}$ standard gallic acid, catechin, caffeine, epicatechin, epigallocatechin gallate, and epicatechin gallate (vacuum drying at $25 \mathrm{C}$ for $24 \mathrm{~h}$, purity $98 \%$, Shanghai Yuanye Biotechnology Co., Ltd., Shanghai, China) was precisely weighed to the nearest $0.01 \mathrm{mg}$, and the standard was placed in a $10 \mathrm{~mL}$ volumetric flask to dissolve and volume with the appropriate amount of methanol. The $12.5 \mathrm{mg}$ of polyphenols extract was accurately weighed and put into a $25 \mathrm{~mL}$ volumetric flask and then methanol was added to dissolve, volume, and shake to obtain $0.5 \mathrm{mg} / \mathrm{mL}$ of test solution. The polyphenol solution was filtered by $0.22 \mu \mathrm{m}$ needle filtration membrane. Under the condition DAD detector; pentafluorophenyl column $(150 \mathrm{~mm} \times 2.1 \mathrm{~mm}, 2.6 \mu \mathrm{m}$, Thermo Fisher Scientific, Inc., Waltham, MA, USA); mobile phase A: $0.1 \%$ formic acid aqueous solution, mobile phase $\mathrm{B}$ : acetonitrile; flow rate: $0.6 \mathrm{~mL} / \mathrm{min}$; column temperature: $30 \mathrm{C}$; injection volume: $10 \mu \mathrm{L}$; detection wavelength: $280 \mathrm{~nm}$ ) of liquid chromatography (UltiMate3000 HPLC System, Thermo Fisher Scientific), the mixed standard was determined [11]. At the same time, the determination was carried out under the above-mentioned liquid chromatography conditions, and the chromatogram information of the test solution was compared (Table 1).

2.3. Animal Experiment. Fifty 6-week-old SPF Kunming mice (males with a body weight of $20 \pm 2 \mathrm{~g}$ ) had a free diet (basic feed) and drinking water with pads changed every 2 days for one week under room temperature conditions of $25 \mathrm{C}$ and relative humidity of $60 \%$. Every two mice were kept in a cage. The mice were divided into five groups: the normal group, model group, low-concentration group (LLTP), highconcentration group (HLTP), and ranitidine group, with 10 mice in each group. The normal group and the model group were given normal saline by gavage, and the mice in the LLTP and HLTP groups were fed LTPs at $100 \mathrm{mg} / \mathrm{kg}$ and $200 \mathrm{mg} / \mathrm{kg}$ by gavage, respectively. The mice in the ranitidine 
TABLE 1: Linear range of liquid chromatography in this study.

\begin{tabular}{lccc}
\hline Standard & Sample quantity $(\mu \mathrm{L})$ & Regression equation & $R^{2}$ \\
\hline Gallic acid & $2^{2}-2^{6}$ & $y=6.5691 x-0.8633$ & 0.9983 \\
Catechin & $2^{2}-2^{6}$ & $y=2.09 x+0.0484$ & 0.9983 \\
Caffeine & $2^{2}-2^{6}$ & $y=2.6679 x+0.0328$ & 0.9989 \\
Epicatechin & $2^{1}-2^{5}$ & $y=1.2862 x+9.4873$ & 0.604 \\
Epigallocatechin gallate & $2^{1}-2^{5}$ & $y=2.81 x+4.2467$ & 0.9989 \\
Epicatechin gallate & $2^{1}-2^{5}$ & $y=2.0218 x+1.0386$ & 0.9983 \\
\hline
\end{tabular}

group were fed ranitidine at a concentration of $50 \mathrm{mg} / \mathrm{kg}$ by gavage for 14 days. On the 14th day, all mice were subjected to fasting for $24 \mathrm{~h}$ after the sample was fed to the mice. On the 15th day, all mice except those in the normal group were administered an ethanol mixture (60\% ethanol and $40 \%$ $150 \mathrm{mmol} / \mathrm{L}$ hydrochloric acid) for $1 \mathrm{~h}$ after being fed first with the sample and then with an ethanol mixture of $0.1 \mathrm{~mL}$ per $10 \mathrm{~g}$ of mouse body weight [12]. After $30 \mathrm{~min}$ of intragastric administration and after anesthesia by injection of $1 \%$ pentobarbital sodium, eyeball blood was collected, and the gastric tissue was dissected for use. The gastric juice was collected with a register and then measured with a $1.2 \mathrm{~mL}$ high-precision measuring cylinder; then the collected gastric juice was measured with a $\mathrm{pH}$ meter (Orion $\mathrm{Star}^{\mathrm{TM}}$ A211, Thermo Fisher Scientific, Inc.) to determine the $\mathrm{pH}$ value. In addition, the degree of gastric mucosal injury was observed intuitively, and the inhibition of gastric injury was calculated from the pictures taken to judge the inhibitory effects of gastric injury using image J 1.44 software. The protocol for these experiments was approved by the Animal Ethics Committee of Chongqing Collaborative Innovation Center for Functional Food, and the animal permit number is 201807008B.

2.4. SOD, GSH, and MDA Level Determination. After blood plasma centrifugation at $4000 \mathrm{rpm}$ for $10 \mathrm{~min}$, the upper serum was collected. The stomachs of the mice were processed into a $10 \%$ homogenate and centrifuged at $4000 \mathrm{rpm}$ for $10 \mathrm{~min}$. The serum and tissue supernatant were used to measure the levels of SOD, GSH, and MDA, which were determined according to the kit instructions (Nanjing Jiancheng Bioengineering Institute, Nanjing, Jiangsu, China).

2.5. Pathology Observation. The stomach tissues $\left(0.5 \mathrm{~cm}^{2}\right)$ of the mice were fixed in $10 \%$ formalin solution for $48 \mathrm{~h}$. The gastric tissues were dehydrated until transparent, embedded in wax and sectioned, and stained with H\&E. The morphological changes of the gastric tissues were observed under an optical microscope (BX43; Olympus, Tokyo, Japan). Dr. Peng Peng is an expert in digestive medicine. He completed the pathological examination of the gastric tissues of mice in this study.

2.6. Quantitative PCR ( $q P C R$ ) Assay. The stomach tissue of mice was crushed; then, the general RNA in the stomach tissue was extracted by RNAzol (Invitrogen, Carlsbad, CA, USA), and the general RNA concentration was diluted to
$1 \mu \mathrm{g} / \mu \mathrm{L}$. Then, from the general diluted $5 \mu \mathrm{L}$ solution, the RNA was extracted and retrieved for use with a reverse transcription kit to obtain the cDNA template. Next, $2 \mu \mathrm{L}$ of the cDNA template was mixed with $10 \mu \mathrm{L}$ of SYBR Green PCR Master Mix and $1 \mu \mathrm{L}$ upstream and downstream primers (Table 2) for reaction at $95 \mathrm{C}$ for $15 \mathrm{~s}$ and $55 \mathrm{C}$ for $30 \mathrm{~s}$ and for 40 cycles at $72 \mathrm{C}$ for $35 \mathrm{~s}$. Finally, the relative expression of the gene was calculated by the $2^{-\Delta \Delta \mathrm{Ct}}$ method with GAPDH as the internal reference at $95 \mathrm{C}$ for $30 \mathrm{~s}$ and $55 \mathrm{C}$ for $35 \mathrm{~s}$ (StepOnePlus Real-Time PCR System; Thermo Fisher Scientific, Waltham, MA, USA) [13].

2.7. Statistical Analysis. Three parallel experiments were carried out on the serum and tissue indexes of each mouse, and the average values were determined. Data are presented as mean \pm standard deviation (SD). Then, the data were analyzed by using SAS 9.1 statistical software. The one-way ANOVA method followed by Duncan's new MRT test was used to determine whether there were significant differences among the groups at the level of $p<0.05$.

\section{Results}

3.1. Components of Polyphenols of LTP. The results show that LTP contains six components, including five polyphenols and one alkaloid. Five kinds of substances were gallic acid, catechin, epicatechin, epigallocatechin gallate, and epicatechin gallate, respectively. The content in LTP was 41.04, $12.98,55.59,134.88$, and $184.76 \mathrm{mg} / \mathrm{g}$. One alkaloid was caffeine, and the content in LTP was $225.56 \mathrm{mg} / \mathrm{g}$ (Figure 1).

3.2. Gastric Juice Volume and $p H$ in Mice. As shown in Table 3, the gastric juice volume of the model group was the largest, and the $\mathrm{pH}$ of the gastric juice was the lowest, while the gastric juice volume of the normal group was the smallest, and the $\mathrm{pH}$ of the gastric juice was the highest. Compared with the model group, both the LTP and ranitidine groups demonstrated a reduction in the gastric juice volume and an increase in the gastric juice $\mathrm{pH}$ in mice with gastric injury, and the effect of the high LTP concentration was similar to that of ranitidine, which can affect the gastric juice volume and gastric juice $\mathrm{pH}$ such that it tends to be normal in mice. LTPs can effectively reduce the increase in gastric juice volume and the decrease in gastric juice $\mathrm{pH}$ caused by gastric injury.

3.3. Observation of Gastric Morphology. Figure 2 and Table 4 show that the gastric mucosa of normal mice was intact with 
TABLE 2: Sequences of primers used in the qPCR assay.

\begin{tabular}{|c|c|}
\hline Gene name & Sequence \\
\hline $\mathrm{Cu} / \mathrm{Zn}-\mathrm{SOD}$ & $\begin{array}{l}\text { Forward: } 5^{\prime} \text {-AACCAGTTGTGTTGTCAGGAC-3' } \\
\text { Reverse: } 5^{\prime} \text {-CCACCATGTTTCTTAGAGTGAGG-3' }\end{array}$ \\
\hline Mn-SOD & $\begin{array}{c}\text { Forward: } 5^{\prime} \text {-CAGACCTGCCTTACGACTATGG-3' } \\
\text { Reverse: } 5^{\prime} \text {-CTCGGTGGCGTTGAGATTGTT-3' }\end{array}$ \\
\hline CAT & $\begin{array}{l}\text { Forward: 5'-GGAGGCGGGAACCCAATAG-3' } \\
\text { Reverse: 5'-GTGTGCCATCTCGTCAGTGAA-3' }\end{array}$ \\
\hline iNOS & $\begin{array}{l}\text { Forward: 5'-AGAGAGATCGGGTTCACA-3' } \\
\text { Reverse: 5'-CACAGAACTGAGGGTACA-3' }\end{array}$ \\
\hline nNOS & $\begin{array}{l}\text { Forward: } 5^{\prime} \text {-TCGTCCAACTTCTGGGCTCTT-3' } \\
\text { Reverse: } 5^{\prime} \text {-CCTTCTCTTCCTCCCCTCTCTTC-3' }\end{array}$ \\
\hline eNOS & $\begin{array}{l}\text { Forward: 5'-TCAGCCATCACAGTGTTCCC-3' } \\
\text { Reverse: } 5^{\prime} \text {-ATAGCCCGCATAGCGTATCAG-3' }\end{array}$ \\
\hline GAPDH & $\begin{array}{c}\text { Forward: 5'-AGGTCGGTGTGAACGGATTTG-3' } \\
\text { Reverse: 5'-GGGGTCGTTGATGGCAACA-3' }\end{array}$ \\
\hline
\end{tabular}

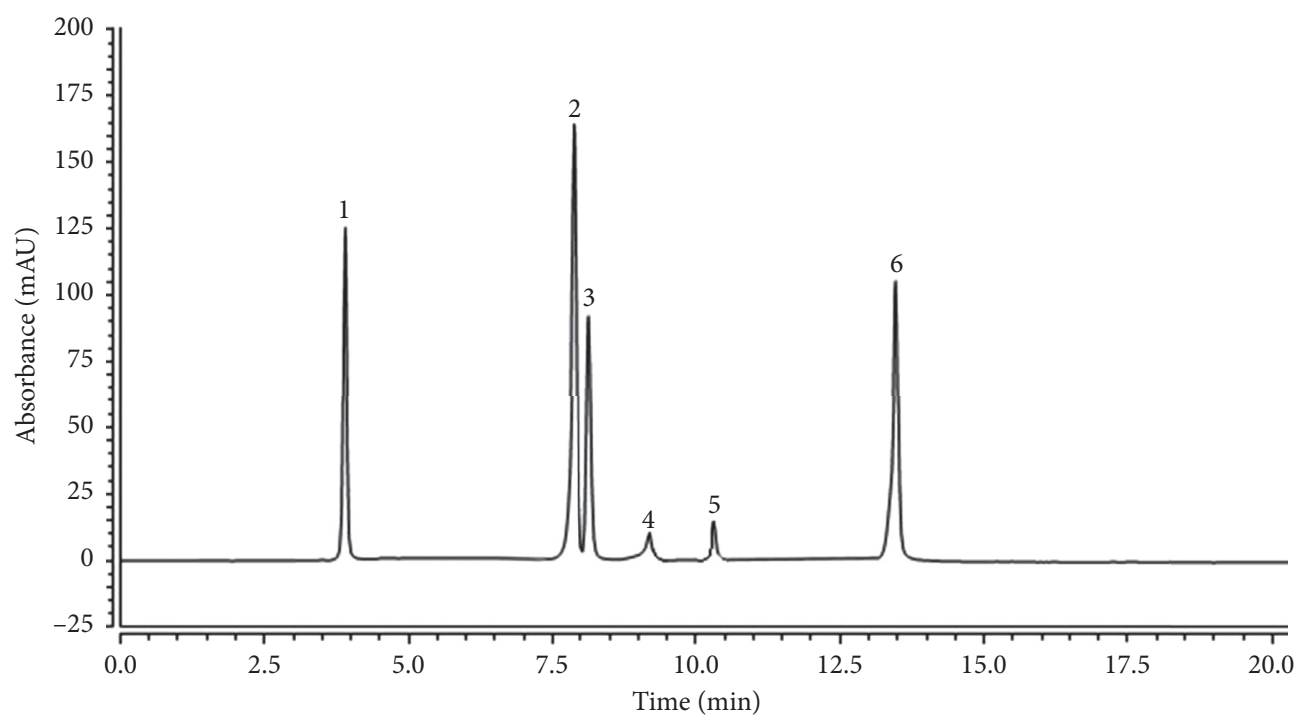

(a)

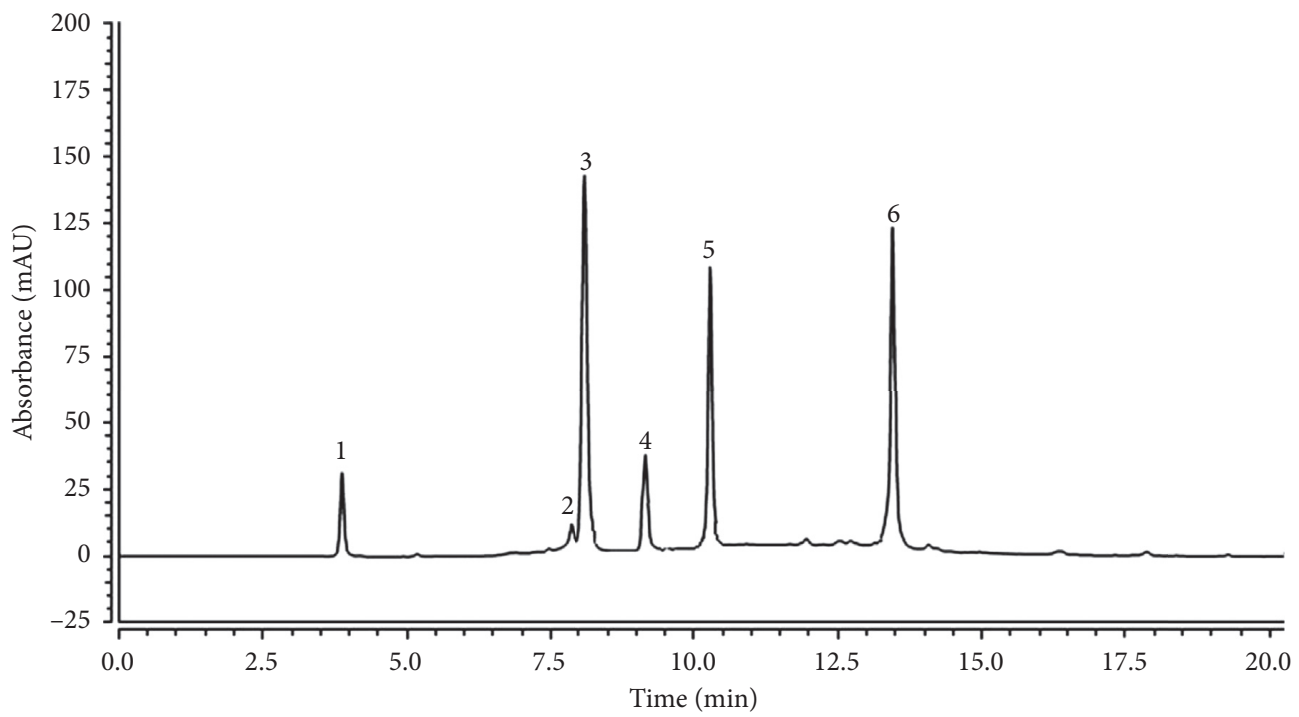

(b)

Figure 1: Polyphenol constituents of Liupao tea. (a) Standard chromatograms. (b) Polyphenols of Liupao tea chromatograms. 1: gallic acid; 2: catechin; 3: caffeine; 4: epicatechin; 5: epigallocatechin gallate; 6: epicatechin gallate. 
TABLe 3: Gastric secretion volume and $\mathrm{pH}$ of gastric juice in mice with gastric injury.

\begin{tabular}{lcc}
\hline Group & Gastric secretion volume $(\mathrm{mL})$ & $\mathrm{pH}$ of gastric juice \\
\hline Normal & $0.12 \pm 0.04^{\mathrm{b}}$ & $4.90 \pm 0.87^{\mathrm{a}}$ \\
Model & $0.23 \pm 0.05^{\mathrm{a}}$ & $3.14 \pm 0.78^{\mathrm{b}}$ \\
Ranitidine & $0.15 \pm 0.04^{\mathrm{ab}}$ & $4.14 \pm 0.90^{\mathrm{ab}}$ \\
LLTP & $0.15 \pm 0.05^{\mathrm{ab}}$ & $4.20 \pm 0.45^{\mathrm{ab}}$ \\
HLTP & $0.16 \pm 0.05^{\mathrm{ab}}$ & $4.52 \pm 0.30^{\mathrm{a}}$ \\
\hline
\end{tabular}

${ }^{\mathrm{a}-\mathrm{b}}$ Mean values with different letters in the same column are significantly different $(p<0.05)$ according to Duncan's new MRT. Ranitidine group: $50 \mathrm{mg} / \mathrm{kg}$ b.w. ranitidine treatment dose; LLTP group: $100 \mathrm{mg} / \mathrm{kg}$ b.w. Liupao tea polyphenols dose; and HLTP group: $200 \mathrm{mg} / \mathrm{kg}$ b.w. Liupao tea polyphenols dose.

normal color and a smooth surface and without bleeding, erosion, or other damage. Ethanol caused a large area of gastric mucosal injury (model group). LTPs and ranitidine could significantly reduce the area of gastric mucosal injury $(p<0.05)$, and the effect of HLTP was stronger than that of LLTP, which was slightly lower than that of ranitidine. Thus, LTPs can effectively reduce the area of alcohol damage to the gastric mucosa and reduce the degree of gastric injury.

3.4. Pathology Observation. As shown in Figure 3, the structure of the gastric tissue in the normal mice is complete. The cells were arranged tightly and orderly, the sizes of the cells were the same, and the surface epithelium was intact and was not detached. In the model group, the structure of the gastric tissue was incomplete. The number of cells was sharply decreased, the arrangement of cells was completely disrupted, the upper epidermis was exfoliated, and serious hemorrhage had occurred in the cells and tissues. In the LLTP group, the cells in the stomach tissue of mice were not uniform in size and were arranged loosely; additionally, some cells were destroyed, evidence of hemorrhage and congestion was observed among the cells, and some of the mucosa was exfoliated. The order and tightness of cells in the HLTP group were more normal than those in the LLTP group. The upper epidermis was more complete, and the congestion and hemorrhage were not as severe compared with the congestion and hemorrhage observed in the LLTP group. In the ranitidine group, the gastric tissue cells were arranged closely, and only individual cells were scattered. Mucosal exfoliation was not obvious, and there was little congestion between the cells and tissues. The results showed that the LTPs could protect gastric tissue and avoid the damage caused by ethanol, and the effect of a high dose was better than that of a low dose.

3.5. SOD, GSH, and MDA Levels. Tables 5 and 6 show that, for the model group, the SOD activity and GSH level were the lowest, and the level of MDA was the highest. The gastric tissue of the normal mice showed the opposite situation; the SOD activity and GSH level in the gastric tissue were the highest, while the level of MDA was the lowest. The LTPs significantly increased SOD activity and GSH level in the gastric tissue of the mice with gastric injury $(p<0.05)$ and decreased the MDA levels $(p<0.05)$, making the index close to that of the normal group. The higher the concentration, the more obvious the effect that was observed, and the higher the concentration of LTPs present, the closer the effect was to that of ranitidine.

3.6. mRNA Expression of Cu/Zn-SOD, Mn-SOD, and CAT. Figure 4 shows that the intensity of the expression of $\mathrm{Cu} / \mathrm{Zn}$ SOD, Mn-SOD, and CAT in the model group was the lowest. The expression of $\mathrm{Cu} / \mathrm{Zn}-\mathrm{SOD}, \mathrm{Mn}-\mathrm{SOD}$, and CAT in the gastric tissues of the mice with gastric injury was significantly increased after the action of LTP $(p<0.05)$. The effect of HLTP was better than that of LLTP, and the effect was close to that of ranitidine.

3.7. mRNA Expression of nNOS, eNOS, and iNOS. Figure 5 shows that the expression of iNOS in the gastric tissue of the normal mice was significantly lower than that of other groups $(p<0.05)$, while the expression levels of nNOS and eNOS were significantly higher than those of other groups. The expression of nNOS, eNOS, and iNOS in the model group showed the opposite trend to that of the normal group. The expression of nNOS and eNOS in the gastric tissues of HLTP- and ranitidine-treated mice was lower than that in normal mice, while the expression of iNOS was higher than that in normal mice.

\section{Discussion}

The alcohol-induced gastric injury model is used to test human gastric acid secretion and imitate alcohol-induced acute digestive injury. This damage model is helpful for studying whether potential bioactive substances have protective and antioxidant effects on the gastric tissue. An ethanol/hydrochloric acid solution can be used to observe the ulceration of the gastric mucosa in mice after gastric damage is induced [14]. After ethanol treatment, the transmembrane potential difference reflecting the gastric mucosal barrier decreased significantly, $\mathrm{Na}^{+}$and $\mathrm{K}^{+}$diffusion into the gastric cavity increased, and $\mathrm{H}^{+}$reverse osmosis also increased. Ethanol can also directly damage the epithelial cells of gastric mucosa, thus damaging the barrier of gastric mucosa, causing $\mathrm{H}^{+}$antidiffusion and further aggravating the damage of gastric mucosa. The combination of hydrochloric acid and ethanol can increase $\mathrm{H}^{+}$in gastric cavity and aggravate gastric injury; that is to say, it can maintain the mechanism of ethanol on gastric injury and enhance the effect, which is convenient to verify the functional function of food [15]. The area of ulceration can be used to determine the degree of gastric injury directly, and other related indicators can be used to determine the degree of gastric injury [14].

Unlike infectious diseases, gastric injury is multifactorial and develops through different contexts, which are mainly caused by different risk factors and unhealthy lifestyles. Ethanol is considered to be an important inducer of human gastric injury, mainly because alcohol easily penetrates and destroys the gastric mucosa, exposing it to gastric acid and pepsinogen. Under the combined action of gastric acid and 


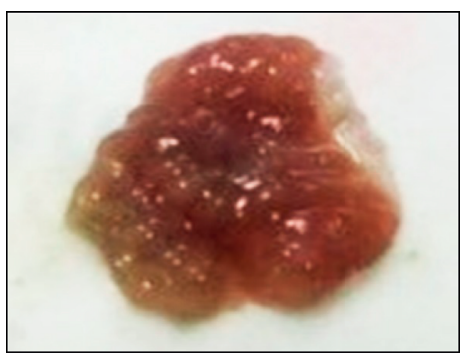

(a)

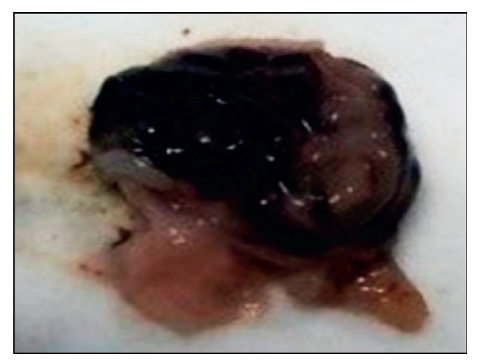

(b)

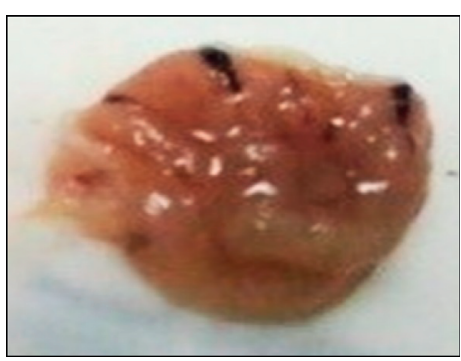

(c)

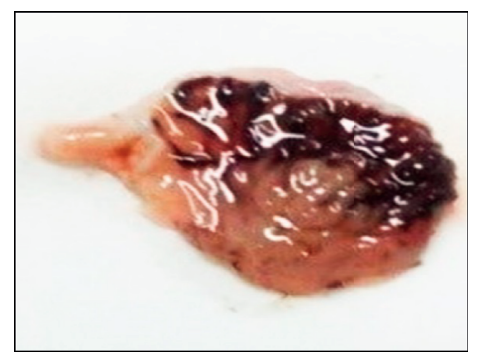

(d)

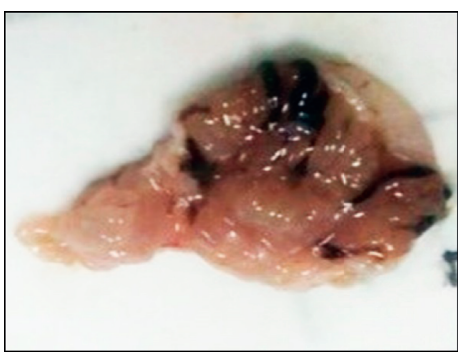

(e)

FIGURE 2: Observation of gastric injury in mice with gastric injury. Ranitidine group: $50 \mathrm{mg} / \mathrm{kg}$ b.w. ranitidine treatment dose; LLTP group: $100 \mathrm{mg} / \mathrm{kg}$ b.w. Liupao tea polyphenols dose; and HLTP group: $200 \mathrm{mg} / \mathrm{kg}$ b.w. Liupao tea polyphenols dose. (a) Normal. (b) Model. (c) Ranitidine. (d) LLTP. (e) HLTP.

TABLE 4: Gastric injury area and inhibition rate of gastric injury in mice.

\begin{tabular}{lcc}
\hline Group & $\begin{array}{c}\text { Gastric injury area } \\
\left(\mathrm{mm}^{2}\right)\end{array}$ & $\begin{array}{c}\text { Gastric injury inhibitory rate (\%) } \\
\text { Normal }\end{array}$ \\
$0.00 \pm 0.00^{\mathrm{e}}$ & $100.00 \pm 0.00^{\mathrm{a}}$ \\
Model & $21.42 \pm 2.75^{\mathrm{a}}$ & $78.21 \pm 2.77^{\mathrm{b}}$ \\
Ranitidine & $4.62 \pm 1.13^{\mathrm{d}}$ & $30.95 \pm 2.04^{\mathrm{d}}$ \\
LLTP & $14.79 \pm 1.49^{\mathrm{b}}$ & $61.20 \pm 2.53^{\mathrm{c}}$ \\
HLTP & $8.31 \pm 1.22^{\mathrm{c}}$ & \\
\hline
\end{tabular}

${ }^{\mathrm{a}-\mathrm{e}}$ Mean values with different letters in the same column are significantly different $(p<0.05)$ according to Duncan's new MRT. Ranitidine group: $50 \mathrm{mg} / \mathrm{kg}$ b.w. ranitidine treatment dose; LLTP group: $100 \mathrm{mg} / \mathrm{kg}$ b.w. Liupao tea polyphenols dose; and HLTP group: $200 \mathrm{mg} / \mathrm{kg}$ b.w. Liupao tea polyphenols dose.

pepsinogen, severe vasoconstriction occurs in a short time and is accompanied by rapid dilation of small arteries. These reactions of blood vessels promote vascular injury and ultimately lead to gastric injury [16]. In the preexperiment, only $100,200,300,400$, and $500 \mathrm{mg} / \mathrm{mL}$ LTP were used to treat the mice, and there was no significant difference in SOD activity among the groups. Under the condition of induced gastric injury, the SOD activity of mice in each group increased with the increase of the concentration of LTP at the concentrations of 100, 200, 300, 400, and $500 \mathrm{mg} /$ $\mathrm{mL}$. According to the statistical data of tea drinking per capita, the concentrations of 100 and $200 \mathrm{mg} / \mathrm{mL} \mathrm{LTP}$ were selected for further study. In this experiment, LTPs effectively reduced the area of gastric injury caused by ethanol/ hydrochloric acid and protected the gastric mucosa. The inhibition rate of gastric injury in the LTP experimental groups was similar to that in the normal group and the ranitidine drug treatment group, indicating that LTPs have a certain preventive effect on the formation of gastric injury.

The inhibition of free radical chain reaction by plant polyphenols is one of the most important mechanisms for plant polyphenols to protect gastric tissue through antioxidant function. Free radical scavenger is an antioxidant that can destroy the reaction chain by reacting with free radicals, in which phenolic hydroxyl group can reduce free radicals by providing an electron; aromatic oxygen free radical compounds are stable due to resonance effect [17]. Polyphenols can enter the lipid bilayer of gastric mucosa cell membrane, so as to protect the whole lipid bilayer from oxidation [18]. The binding of polyphenols to lipid bilayers and membrane proteins can affect the electrical properties of membrane. The change of membrane fluidity caused by polyphenols can inhibit inflammation [19]. These effects might also be reflected in the protection of gastric tissue by LTP.

Normally, gastric juices do not affect the gastric mucosa. After gastric mucosa injury, however, the stomach is stimulated and secretes many gastric acids, which increase the volume of gastric juice in the stomach and decrease the $\mathrm{pH}$ of the gastric juice, leading to the aggravation of damage to the gastric mucosa and thus causing a vicious circle of exacerbated damage to the stomach [20]. In this study, LTPs could effectively reduce the volume of gastric juice and increase the $\mathrm{pH}$ of the gastric juice in mice with gastric injury, thus protecting the gastric tissue and alleviating the alcohol-induced gastric injury.

The neurotype, endothelial type, and inducible type of NOS are nNOS, eNOS, and iNOS, respectively. NOS is the rate-limiting enzyme of NO synthesis and widely exists in 


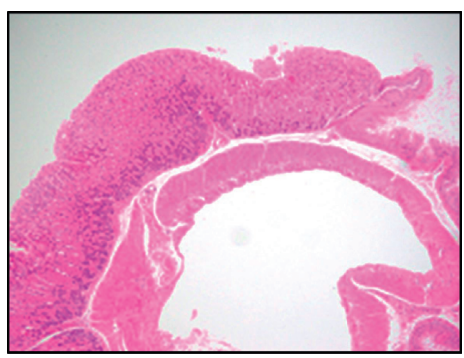

(a)

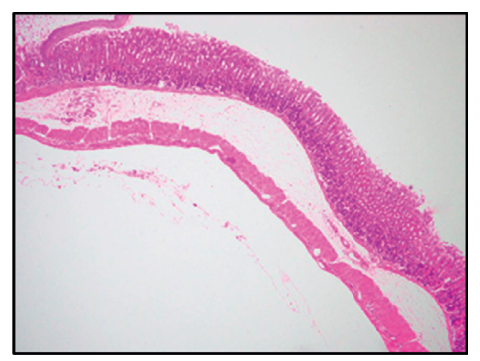

(b)

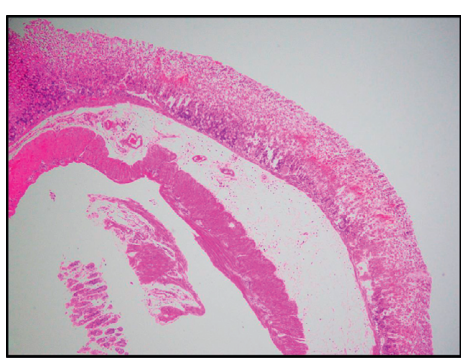

(c)

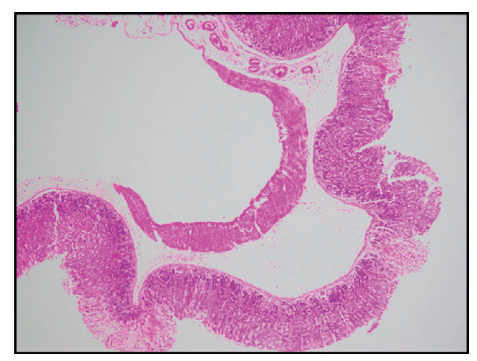

(d)

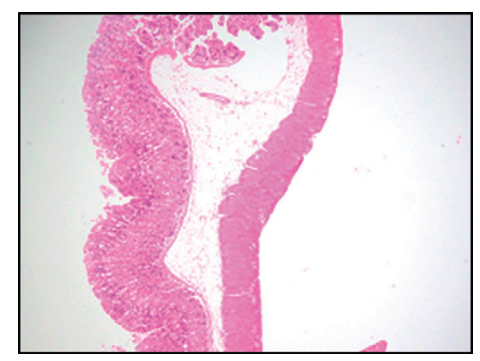

(e)

Figure 3: Pathological observation of gastric injury in mice with gastric injury. Ranitidine group: $50 \mathrm{mg} / \mathrm{kg}$ b.w. ranitidine treatment dose; LLTP group: $100 \mathrm{mg} / \mathrm{kg}$ b.w. Liupao tea polyphenols dose; and HLTP group: $200 \mathrm{mg} / \mathrm{kg}$ b.w. Liupao tea polyphenols dose. (a) Normal. (b) Model. (c) Ranitidine. (d) LLTP. (e) HLTP.

TABLE 5: SOD, GSH, and MDA levels in serum of mice with gastric injury.

\begin{tabular}{lccc}
\hline Group & SOD $(\mathrm{U} / \mathrm{mL})$ & GSH $(\mathrm{mg} / \mathrm{mL})$ & MDA $(\mathrm{nmol} / \mathrm{mL})$ \\
\hline Normal & $169.72 \pm 15.12^{\mathrm{a}}$ & $1.25 \pm 0.12^{\mathrm{a}}$ & $11.29 \pm 1.09^{\mathrm{e}}$ \\
Model & $71.52 \pm 5.33^{\mathrm{c}}$ & $0.43 \pm 0.06^{\mathrm{d}}$ & $41.77 \pm 3.85^{\mathrm{a}}$ \\
Ranitidine & $111.87 \pm 8.16^{\mathrm{b}}$ & $1.14 \pm 0.11^{\mathrm{ab}}$ & $21.93 \pm 2.03^{\mathrm{d}}$ \\
LLTP & $83.20 \pm 8.06^{\mathrm{bc}}$ & $0.75 \pm 0.07^{\mathrm{c}}$ & $34.59 \pm 2.81^{\mathrm{b}}$ \\
HLTP & $105.38 \pm 7.14^{\mathrm{b}}$ & $1.05 \pm 0.09^{\mathrm{b}}$ & $26.81 \pm 1.83^{\mathrm{c}}$ \\
\hline
\end{tabular}

${ }^{\mathrm{a}-\mathrm{e}}$ Mean values with different letters in the same column are significantly different $(p<0.05)$ according to Duncan's new MRT. Ranitidine group: $50 \mathrm{mg} / \mathrm{kg}$ b.w. ranitidine treatment dose; LLTP group: $100 \mathrm{mg} / \mathrm{kg}$ b.w. Liupao tea polyphenols dose; and HLTP group: $200 \mathrm{mg} / \mathrm{kg}$ b.w. Liupao tea polyphenols dose.

the normal tissues of humans and animals [21]. Under normal physiological conditions, the mechanism of $\mathrm{NO}$ production, release, diffusion, and inactivation is precisely regulated in the nervous system, largely through the activation and deactivation of nNOS [22]. nNOS plays an important role in the nervous system and is distributed in gastric mucosal epithelial cells. nNOS regulates blood flow and muscle contraction by regulating NO to control the degree of gastric injury. The decrease in nNOS levels leads to the aggravation of gastric tissue damage [23]. The expression and activity of eNOS are relatively stable. NO derived from eNOS is mainly involved in promoting epithelial repair, regulating gastric mucosal blood flow and adaptive cell protection by inhibiting gastric acid secretion, enhancing mucus barrier function, and promoting vascular regeneration [24]. In addition, eNOS can inhibit the oxidative damage in blood vessels caused by oxidative stress and can relax and protect blood vessels [25]. Once iNOS is activated, the enzymatic activity will last for a long time and produce a large amount of NO. A low concentration of NO can effectively help cells resist gene mutation and can activate the defense ability of the organism, but a high concentration of NO causes loss of gene mutation control, stimulates gene mutation and aggravates tissue damage [26]. LTPs can increase the expression of nNOS and eNOS in the gastric tissue of mice with gastric injury and reduce the expression of iNOS, thus inhibiting the inflammatory response, protecting gastric mucosa, and inhibiting gastric injury.

Oxidative stress is the main characteristic of gastric mucosal injury. It has been shown that the damage of gastric mucosal cells is aggravated by a decrease in antioxidants such as SOD, CAT, and GSH after ethanol treatment. As a responsive element to free radical accumulation, SOD and other cell antioxidant enzymes are considered the first line of defense against oxidative damage. CAT and GSH have similar effects as SOD and can clear free radicals in the body over time to maintain the balance between oxidation and antioxidation and protect the body from free radical damage. Therefore, the level of antioxidant enzymes can directly reflect the number of free radicals in the body $[27,28]$. Cu/ $\mathrm{Zn}-\mathrm{SOD}$ is found mainly in the cytoplasm, while Mn-SOD is found mainly in mitochondria. They have different sensitivities to different factors [29]. After ethanol injury to the gastric mucosa, the activity of SOD, CAT, and GSH in the body will decrease significantly [14]. The decreased activity of these antioxidant enzymes may trigger lipid chain peroxidation, which results in decreased fluidity and enhanced permeability of biofilms. MDA is produced by lipid decomposition of peroxide; therefore, the MDA level is often used as a marker of lipid peroxidation, and it reacts with free radical production [30]. In this study, the activity of SOD and GSH in the serum and gastric tissues of the mice with 
TABLE 6: SOD, GSH, and MDA levels in gastric tissue of mice with gastric injury.

\begin{tabular}{lccc}
\hline Group & SOD (U/mgprot) & GSH $(\mu \mathrm{g} /$ gprot $)$ & MDA (nmol/mgprot) \\
\hline Normal & $208.63 \pm 18.32^{\mathrm{a}}$ & $657.58 \pm 35.17^{\mathrm{a}}$ & $2.86 \pm 0.29^{\mathrm{e}}$ \\
Model & $125.67 \pm 12.06^{\mathrm{d}}$ & $314.08 \pm 18.44^{\mathrm{d}}$ & $8.16 \pm 0.62^{\mathrm{a}}$ \\
Ranitidine & $171.42 \pm 6.91^{\mathrm{b}}$ & $528.71 \pm 30.86^{\mathrm{b}}$ & $4.19 \pm 0.36^{\mathrm{d}}$ \\
LLTP & $140.55 \pm 7.02^{\mathrm{c}}$ & $442.93 \pm 29.68^{\mathrm{c}}$ & $7.05 \pm 0.31^{\mathrm{b}}$ \\
HLTP & $164.39 \pm 10.11^{\mathrm{b}}$ & $519.80 \pm 32.05^{\mathrm{b}}$ & $5.41 \pm 0.22^{\mathrm{c}}$ \\
\hline
\end{tabular}

${ }^{\mathrm{a}-\mathrm{e}}$ Mean values with different letters in the same column are significantly different $(p<0.05)$ according to Duncan's new MRT. Ranitidine group: $50 \mathrm{mg} / \mathrm{kg}$ b.w. ranitidine treatment dose; LLTP group: $100 \mathrm{mg} / \mathrm{kg}$ b.w. Liupao tea polyphenols dose; and HLTP group: $200 \mathrm{mg} / \mathrm{kg}$ b.w. Liupao tea polyphenols dose.

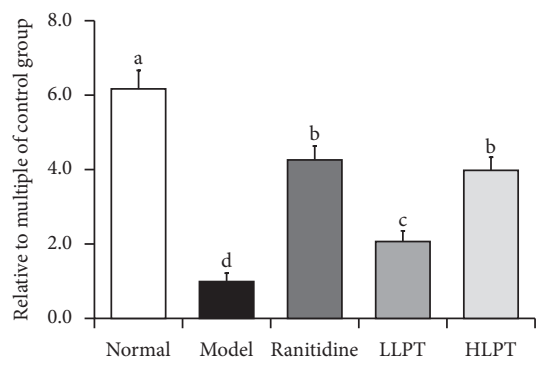

(a)

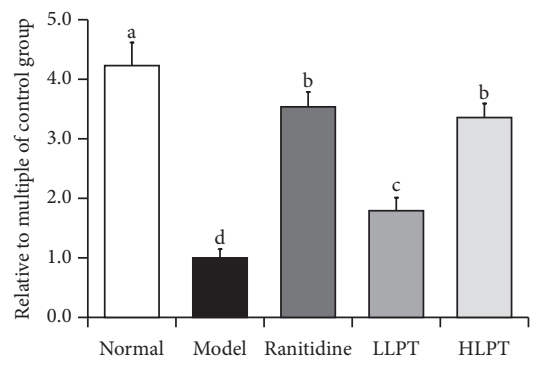

(b)

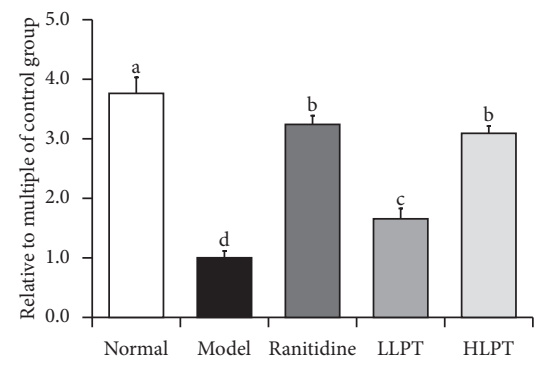

(c)

Figure 4: The mRNA expression level of (a) Cu/Zn-SOD, (b) Mn-SOD, and (c) CAT in the gastric tissue of mice. Values presented are the mean \pm standard deviation. ${ }^{a-c}$ Mean values with different letters in the bar are significantly different $(p<0.05)$ according to Duncan's new MRT. Ranitidine group: $50 \mathrm{mg} / \mathrm{kg}$ b.w. ranitidine treatment dose; LLTP group: $100 \mathrm{mg} / \mathrm{kg}$ b.w. Liupao tea polyphenols dose; and HLTP group: $200 \mathrm{mg} / \mathrm{kg}$ b.w. Liupao tea polyphenols dose.

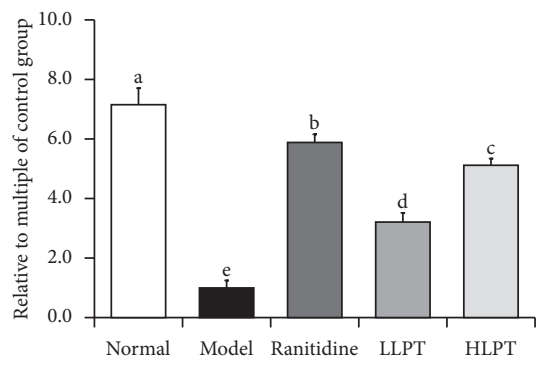

(a)

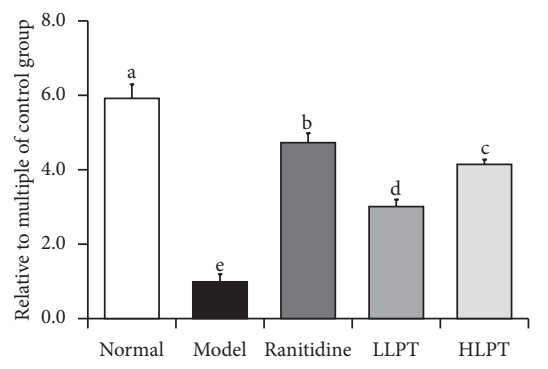

(b)

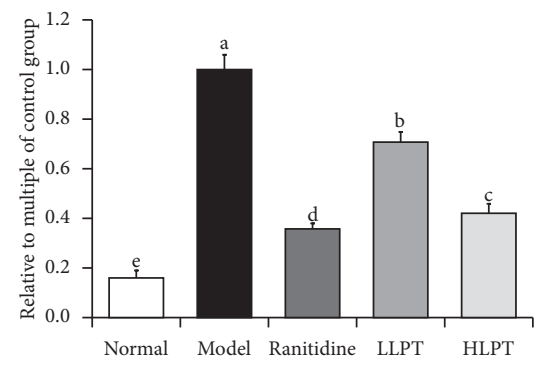

(c)

Figure 5: The mRNA expression level of (a) nNOS, (b) eNOS, and (c) iNOS in the gastric tissue of mice. Values presented are the mean \pm standard deviation. ${ }^{\mathrm{a}-\mathrm{c}}$ Mean values with different letters in the bar are significantly different $(p<0.05)$ according to Duncan's new MRT. Ranitidine group: $50 \mathrm{mg} / \mathrm{kg}$ b.w. ranitidine treatment dose; LLTP group: $100 \mathrm{mg} / \mathrm{kg}$ b.w. Liupao tea polyphenols dose; and HLTP group: $200 \mathrm{mg} / \mathrm{kg}$ b.w. Liupao tea polyphenols dose.

gastric injury after LTP treatment was significantly higher than that in the model group, and the MDA content was significantly lower than that of the model group. Further experiments confirmed that LTP could upregulate the expression of $\mathrm{Cu} / \mathrm{Zn}-\mathrm{SOD}, \mathrm{Mn}-\mathrm{SOD}$, and CAT in the gastric tissues of the mice with gastric injury, indicating that LBTP could reduce the free radical damage caused by ethanol, reduce lipid peroxidation, protect the antioxidant balance, and inhibit the gastric injury caused by alcohol.

Gallic acid can inhibit oxidative stress and inflammation to improve gastric injury [31]. Catechins can also protect tissues by reducing the content of malondialdehyde and increasing the activity of superoxide dismutase [32]. Epicatechin also has the effect of alleviating the disease through its antioxidation function. At the same time, epicatechin can also reduce the expression of inflammation related, so as to alleviate the inflammatory response of tissue [33]. Epigallocatechin gallate is the main component of tea polyphenols. It has strong antioxidant effect, which can inhibit inflammation and protect the body from oxidative stress $[33,34]$. Epicatechin gallate shows a better antioxidant effect than epigallocatechin gallate, thus protecting the body and reducing oxidative damage and inflammation [33, 35]. Caffeine is not a polyphenol, it is an alkaloid, but it is often extracted together in the separation of tea polyphenols [33]. Caffeine can reduce inflammation-related cytokines and reduce the damage of inflammation to the body, especially caused by alcohol $[33,36]$. Because of the combined action of 
these five polyphenols and an alkaloid, it had a good antioxidant effect, thus played a role in reducing gastric injury and protecting gastric tissue.

In this study, LTPs were studied in mice with gastric injury, and the indexes of serum and gastric tissue corresponding to LTP treatment were determined. The results showed that LTP could significantly repair the abnormal indexes of gastric injury, regulate the oxidative stress in serum and gastric tissue to close to normal levels, regulate the expression of the related mRNA in gastric tissue, and attenuate the gene expression in gastric tissue to near normal such that it repairs the effects of the gastric injury on gastric tissue. The results also showed that LTPs had a good effect of preventing gastric injury, and the intensity of this protection depended on the concentration of the LTPs. The higher the concentration was, the stronger the preventive effect of LTPs on gastric injury was. Therefore, LTPs represent a kind of bioactive ingredient with good gastric tissue protection. LTPs can be used and developed as active substances to prevent alcohol-induced gastric injury; particularly, LTPs can be used as bioactive ingredients in treatment for people with alcoholism or for chronic $\mathrm{HCl} /$ ethanol induced gastric injury repair.

\section{Data Availability}

No data were used to support this study.

\section{Conflicts of Interest}

The authors declare no conflicts of interest.

\section{Authors' Contributions}

Kai Zhu and Peng Peng contributed equally to this work. Kai Zhu and Peng Peng performed the majority of the experiments and wrote the manuscript. Ning Wu, Xianrong Zhou, and Jianfei $\mathrm{Mu}$ contributed to the data analysis. Xin Zhao designed and supervised the study and read the final manuscript.

\section{Acknowledgments}

This study was supported by the Introduction of High Level Personnel Research Start-Up Fund of Chongqing University of Education (2013BSRC001) and the Scientific Research Foundation for Returned Overseas Chinese Scholars and the State Education Ministry (Jiaowaisiliu (2014)1685), China.

\section{References}

[1] X. L. Liu, Y. Li, Y. X. Jiang, and X. Yu, "Analysis on feature composition of Guangxi Liupao tea," Journal of Beijing Technology and Business University (Natural Science Edition), vol. 30, no. 1, pp. 46-50, 2012.

[2] L. Huang, J. J. Peng, N. Xia, J. W. Teng, and B. Y. Wei, "Effect on regulation of hyperlipidemia and anticoagulant for Liupu tea," Food Science and Technology, vol. 38, no. 8, pp. 123-127, 2013.

[3] X. Y. Zhang, Y. S. Huang, G. P. Liu, W. Y. Rao, L. Qin, and Y. Y. Deng, "The effects of Liupao tea on blood lipid and antioxidation and hyperlipidemia mice," Journal of Medical Theory and Practice, vol. 26, no. 5, pp. 563-564, 2013.

[4] Y. Y. Zhao, L. Huang, B. Y. Wei, J. W. Teng, and N. Xia, "Effect of Liupao tea extract on fecal microbiota in hyperlipidemic mice," Science and Technology of Food Industry, vol. 36, no. 21, pp. 364-367, 2015.

[5] Q. Q. Teng, Z. H. Liu, S. J. Gong, Y. X. Peng, and R. Ma, "Effect of Liupao Tea on glucose and lipid metabolism in palmitateinduced insulin resistance 3T3-L1 adipocytes," Journal of Tea Science, vol. 34, no. 3, pp. 230-238, 2014.

[6] J. Q. Liu, W. F. Shao, B. Q. Zhao et al., "Study of fermented puerh tea powder, dark tea powder and liupu tea on losing weight in hyperlipidemia model rats," China Journal of Traditional Chinese Medicine and Pharmacy, vol. 29, no. 1, pp. 108-112, 2014.

[7] A. Rocco, D. Compare, D. Angrisani, M. Sanduzzi Zamparelli, and G. Nardone, "Alcoholic disease: liver and beyond," World Journal of Gastroenterology, vol. 20, no. 40, pp. 14652-146529, 2014.

[8] K. Balusikova and J. Kovar, "Alcohol dehydrogenase and cytochrome P450 2E1 can be induced by long-term exposure to ethanol in cultured liver HEP-G2 cells," In Vitro Cellular \& Developmental Biology-Animal, vol. 49, no. 8, pp. 619-625, 2013.

[9] M. Tamura, H. Matsui, T. Kaneko, and I. Hyodo, "Alcohol is an oxidative stressor for gastric epithelial cells: detection of superoxide in living cells," Journal of Clinical Biochemistry and Nutrition, vol. 53, no. 2, pp. 75-80, 2013.

[10] X. Zhao and Y. Qian, "Preventive effects of kuding tea crude polyphenols in DSS-induced C57BL/6J mice ulcerative colitis," Science and Technology of Food Industry, vol. 38, no. 9, pp. 357-362, 2017.

[11] B. H. Liu, R. D. MA, J. Zhang, P. Sun, R. K. Yi, and X. Zhao, "Preventive effect of small-leaved Kuding tea (Ligustrum robustum (Roxb.) Bl.) polyphenols on D-galactose-induced oxidative stress and aging in mice," Evidence-Based Complementary and Alternative Medicine, vol. 2019, Article ID 3152324, 13 pages, 2019.

[12] S. Mathews, M. Xu, H. Wang, A. Bertola, and B. Gao, "Animals models of gastrointestinal and liver diseases. Animal models of alcohol-induced liver disease: pathophysiology, translational relevance, and challenges," American Journal of Physiology-Gastrointestinal and Liver Physiology, vol. 306, no. 10, pp. 819-823, 2014.

[13] S. Asfar, S. Abdeen, H. Dashti et al., "Effect of green tea in the prevention and reversal of fasting-induced intestinal mucosal damage," Nutrition, vol. 19, no. 6, pp. 536-540, 2003.

[14] C. Mota, R. Freitas, M. Athayde et al., "Effect of Vernonia cognata on oxidative damage induced by ethanol in rats," Human \& Experimental Toxicology, vol. 30, no. 7, pp. 675684, 2011.

[15] Y. B. Zhang, Y. S. Ruan, X. H. Zhao, and C. Liu, "The research progress of gastric mucosal damage induced by ethanol and its protective effects," Journal of Food Safety \& Quality, vol. 2013, no. 4, pp. 1239-1245, 2013.

[16] B. Taylor and J. Rehm, "Moderate alcohol consumption and diseases of the gastrointestinal system: a review of pathophysiological processes," Digestive Diseases, vol. 23, no. 3-4, pp. 177-180, 2005.

[17] W. Bors, W. Heller, C. Michel, and M. Saran, "[36] Flavonoids as antioxidants: determination of radical-scavenging efficiencies," Oxygen Radicals in Biological Systems Part B: Oxygen Radicals and Antioxidants, vol. 186, pp. 343-355, 1990. 
[18] S. Yano, Y. Fujimura, D. Umeda, T. Miyase, K. Yamada, and H. Tachibana, "Relationship between the biological activities of methylated derivatives of (-)-epigallocatechin-3-O-gallate (EGCG) and their cell surface binding activities," Journal of Agricultural and Food Chemistry, vol. 55, no. 17, pp. 71447148, 2007.

[19] H. Tsuchiya, M. Nagayama, T. Tanaka, M. Furusawa, M. Kashimata, and H. Takeuchi, "Membrane-rigidifying effects of anti-cancer dietary factors," Biofactors, vol. 16, no. 3-4, pp. 45-56, 2002.

[20] B. H. Liu, X. X. Feng, J. Zhang, Y. Wei, and X. Zhao, "Preventive effect of Anji White tea flavonoids on alcohol-induced gastric injury through their antioxidant effects in kunming mice," Biomolecules, vol. 9, no. 4, p. 137, 2019.

[21] H. B. Liu, X. D. Huang, M. H. Liu, and J. Y. Shanguan, "Significance of NOS expressions in gastric carcinoma," Medical Journal of National Defending Forces In Northwest China, vol. 23, no. 2, pp. 115-117, 2002.

[22] L. J. Ignarro, R. E. Byrns, D. Sumi, F. de Nigris, and C. Napoli, "Pomegranate juice protects nitric oxide against oxidative destruction and enhances the biological actions of nitric oxide," Nitric Oxide, vol. 15, no. 2, pp. 93-102, 2006.

[23] O. A. El-Gohary, "Obestatin improves hepatic injury induced by ischemia/reperfusion in rats: role of nitric oxide," General Physiology and Biophysics, vol. 36, no. 1, pp. 109-115, 2017.

[24] M. Bachmann, Z. Waibler, T. Pleli, J. Pfeilschifter, and H. Mühl, “Type I interferon supports inducible nitric oxide synthase in murine hepatoma cells and hepatocytes and during experimental acetaminophen-induced liver damage," Frontiers in Immunology, vol. 8, p. 890, 2017.

[25] X. Zhao, P. Sun, G. Li, R. Yi, Y. Qian, and K.-Y. Park, "Polyphenols in Kuding tea help prevent $\mathrm{HCl} /$ ethanol-induced gastric injury in mice," Food \& Function, vol. 9, no. 3, pp. 1713-1725, 2018.

[26] Y. Qian, J. Zhang, X. Fu et al., "Preventive effect of raw Liubao tea polyphenols on mouse gastric injuries induced by $\mathrm{HCl}$ / ethanol via anti-oxidative stress," Molecules, vol. 23, no. 11, p. $2848,2018$.

[27] R. Yi, R. Wang, P. Sun, and X. Zhao, "Antioxidant-mediated preventative effect of Dragon-pearl tea crude polyphenol extract on reserpine-induced gastric ulcers," Experimental and Therapeutic Medicine, vol. 10, no. 1, pp. 338-344, 2015.

[28] K.-L. Kuo, M.-S. Weng, C.-T. Chiang, Y.-J. Tsai, S.-Y. LinShiau, and J.-K. Lin, "Comparative studies on the hypolipidemic and growth suppressive effects of oolong, black, pu-erh, and green tea leaves in rats," Journal of Agricultural and Food Chemistry, vol. 53, no. 2, pp. 480-489, 2005.

[29] D. J. Bonthius Jr., Z. Winters, B. Karacay, S. L. Bousquet, and D. J. Bonthius, "Importance of genetics in fetal alcohol effects: null mutation of the nNOS gene worsens alcohol-induced cerebellar neuronal losses and behavioral deficits," Neurotoxicology, vol. 46, pp. 60-72, 2015.

[30] S. Pillai, C. Oresajo, and J. Hayward, "Ultraviolet radiation and skin aging: roles of reactive oxygen species, inflammation and protease activation, and strategies for prevention of inflammation-induced matrix degradation-a review," International Journal of Cosmetic Science, vol. 27, no. 1, pp. 17-34, 2005.

[31] C. Pal, S. Bindu, S. Dey et al., "Gallic acid prevents nonsteroidal anti-inflammatory drug-induced gastropathy in rat by blocking oxidative stress and apoptosis," Free Radical Biology and Medicine, vol. 49, no. 2, pp. 258-267, 2010.

[32] W. Zhai, J. H. Zheng, X. D. Yao et al., "Catechin prevents the calcium oxalate monohydrate induced renal calcium crystallization in NRK-52E cells and the ethylene glycol induced renal stone formation in rat," BMC Complementary and Alternative Medicine, vol. 13, no. 228, 2013.

[33] Y. N. Pan, X. Y. Long, R. K. Yi, and X. Zhao, "Polyphenols in Liubao tea can prevent $\mathrm{CCl}_{4}$-induced hepatic damage in mice through its antioxidant capacities," Nutrients, vol. 10, no. 9, p. 1280, 2018.

[34] D. M. Liu and X. F. Wang, "EGCG influences the NF- $\kappa$ B and ICAM-I expression of ConA inducing liver injury," Anatomy Research, vol. 36, no. 1, pp. 27-30, 2014.

[35] X. N. Zhang, Y. Lin, J. A. Huang, Z. H. Liu, and D. D. Liang, "Inhibitory effects of tea extracts EGCG, GCG and ECG on the melanogenesis in melanoma cell B16," Journal of Hunan Agricultural University, vol. 43, no. 4, pp. 405-410, 2017.

[36] Z. Chen, X. W. Lv, J. Li et al., "Protective effect of caffeine on alcohol-induce acute liver injury in mice," Acta Universitatis Medicinalis Anhui, vol. 44, no. 3, pp. 359-362, 2009. 